\title{
Analyzing the Key Drivers of Contractors' Temporary Competitive Advantage in the Competition of International High-speed Rail Projects
}

\author{
Qianwen Zhou' ${ }^{1}$, Xiaopeng Deng ${ }^{2}$, Ruoyu $\mathrm{Jin}^{3}$ and Tengyuan Chang ${ }^{4}$
}

\begin{abstract}
After temporary competitive advantage (TCA) being proposed, this concept has received extensive attention from academia and industry. For international HSR contractors, how to form their TCA and win out over the competition for new projects is crucial, while only few studies focus on this issue. The aim of this research is to develop a TCA system that reflects the characteristics of high-speed rail (HSR) contractors from corporation and project dimension. At first, exploratory factor analysis (EFA) and confirmatory factor analysis (CFA) were conducted to explore and examine the key drivers and their relationships with contractors' TCA. The results revealed that experience-mining advantage was the most important factor of the six common factors. Next, common factors were divided into three dimensions and discussed in depth, including resource-based TCA (i.e., technical resource and social image) which had the highest significance, followed by performance-based TCA (experience-mining advantage and risk-controlling

\footnotetext{
1 Ph.D. Candidate, Scholl of Civil Engineering, Southeast University, Civil Engineering Building 1104, Nanjing, Jiangsu Province, P.R.C (E-mail: 230189106@seu.edu.cn)

${ }^{2}$ Corresponding author. Professor, Scholl of Civil Engineering, Southeast University, Civil Engineering Building 1111, Nanjing, Jiangsu Province, P.R.C (E-mail: dxp@seu.edu.cn)

${ }^{3}$ Senior Lecturer, School of Environment and Technology, University of Brighton, Cockcroft Building 616, Brighton, UK (Email: R.Jin@brighton.ac.uk)

4 Ph.D. Candidate, Scholl of Civil Engineering, Southeast University, Civil Engineering Building 1104, Nanjing, Jiangsu Province, P.R.C (E-mail: changty@seu.edu.cn)
} 
performance), and action-based TCA (i.e., funding strategy and organizational management).

Finally, two case study projects were selected to investigate the competition situation between CRH (China Railway High-speed) and Shinkansen (Japan) in the international HSR market. This study not only provides suggestions for contractors to improve their TCA in international HSR projects, but also contributes to the theoretical framework for TCA theory.

Keywords: High-speed rail (HSR) project; international contractors; temporary competitive advantage (TCA); factor analysis; case study

\section{Introduction}

In recent years, high-speed rail (HSR) entered a vigorous period of development and many countries have made HSR construction plans, including "High-Speed Railway Strategic Plan" made by U.S. Department of Transportation, "2050” transportation strategy formulated by Europe, etc., showing that HSR is in high demand in many countries (Zhou et al., 2014). However, huge market demand has also attracted many competitors, competition between several HSR systems grows keener (Zhang et al., 2019). HSR is generally larger in scale, longer in the construction period, and with more considerable regional differences, so bidders often work in a form of international consortia or joint ventures (Hwang et al., 2018). Therefore, it is necessary for contractors to fully extract the advantages accumulated by each member over the years, then integrate and maximize the use of them according to the specific competition environment, thus forming their advantages at a particular time, which is the process of forming HSR contractors' temporary competitive advantage (TCA).

TCA, considered as the ability of companies to surpass their competitors, gain market dominance 
and high profitability levels when facing a particular competitive environment, so as to ensure that they can gain superiority in the competition within a certain period of time (Mcgrath, 2013; Huang et al., 2015). After O'Shannassy (2008) proposed that all competitive advantages are temporary in the complex and ever-changing environment, TCA has been valued and discussed over the past decade. For example, Lee et al. (2010) used the software industry as an example to analyze super-competition, and proposed that managing dynamic capabilities is the key to update short-term advantages. Leavy (2014) explored the necessity to study TCA from four different dimensions: strategy, philosophy, organization, and leadership. Therefore, companies need to respond quickly to environmental changes in every dimension. Unfortunately, most previous research on TCA has focused on two aspects, industry and enterprise (Chan, 2004; Agnihotri and Rapp, 2011), while few studies involved the contractors' TCA in the project competition.

As suggested by D'Aveni et al. (2010), the time has come when enterprises pursue TCA, which will become the core issue in the field of strategic management. Due to the one-off nature of the project, and the ultra-competitive environment of the HSR industry, HSR contractors should improve their TCA by integrating resources, accumulating experience, and adjusting strategies etc. Therefore, this study aims to identify the critical variables contributing to contractors' TCA in the competition of international HSR projects and develop an integrated TCA system that reflects the specialty of HSR contractors from corporation and project dimension.

The rest of this research is structured as follows: Section 2 reviews the related literature. A brief introduction of the overall research framework and the results of factor analysis are presented in sections 3 and 4, respectively. Section 5 discusses six components in depth. Section 6 selects several 
HSR projects to prove the practice value of the factor system. Section 7 provides concluding remarks and directions for future research. This paper helps contractors better understand the advantages and disadvantages they have compared to other competitors, and provides a reference for project clients to select the best contractor. Moreover, due to the unique nature of international HSR projects, this paper also contributes to the theoretical framework for TCA.

\section{Literature Review}

\subsection{Temporary Competitive Advantage (TCA)}

The research on the competitive advantage dates back to the mid-1980s (Porter, 1985). Through several decades of development, this theory has matured. However, many researchers have found that the increasing market competition and the rapid shift in customer demand make it difficult for companies to maintain sustainable competitive advantage (SCA) (Ram et al., 2014), especially for fast-internationalizing technology-intensive companies. Therefore, SCA starts being questioned, with some scholars proposing TCA (O'Shannassy, 2008). Thomas and D'Aveni (2009) found that the temporary part of competitive advantage is rising compared to the long-term component of competitive advantage. McGrath (2013) proposed six strategies to achieve TCA, including removing industry restrictions, adopting new standards and supporting innovation activities, focusing on customer experiences and solutions, etc.

Based on the review of related literature, the TCA theory can be divided into three major research categories: action-based TCA, resource-based TCA and performance-based TCA. In terms of action-based TCA, Lavie (2006) proposed that long-term success requires dynamic actions to create, destroy, and recreate short-term advantages continually. Therefore, companies should not only hit 
the TCA of their competitors but also actively update their own TCA (Chen et al., 2012). The resource-based theory assumed that the competitive advantage of the enterprise comes from valuable, scarce, non-imitation, irreplaceable resources (Lavie, 2006). However, in many high-tech industries, the transfer and diffusion of technical resources is rapid, hence companies are looking for new resources to replace the old ones, which can help them create TCA (Derfus et al., 2008). As for performance-based TCA theory, Thomas and D'Aveni (2009) proposed that the volatility of corporate performance increased over time, indicating that the short-term effects of competitive advantage are becoming more apparent. Overall, the research of the three genres is mainly from the perspective of the enterprise, including business operations (based on resources), processes (based on actions) and results (based on performance). D'Aveni et al. (2010) believed that it is necessary to combine these three genres to conduct more comprehensive and reasonable research. To conclude, despite the theoretical basis of TCA that has been clarified in the previous study, there are few studies on the application of TCA theory.

\subsection{Contractors' Temporary Competitive Advantage (TCA)}

In the increasingly competitive international construction market, contractors must analyze their competitiveness to determine their competitive advantage (Tan, 2011; Alzahrani and Emsley, 2013). Understanding the sources and drivers of competitive advantage is essential for proposing appropriate strategies. Many studies are exploring or examining the critical success factors (CSFs) of contractors' competitiveness. For instance, Lu et al. (2008) identified 35 CSFs for the competitiveness of contractors and classified them into eight categories by factor analysis, including project management, organization structure, organization resources, competitive strategy, 
101

102

103

relationship, bidding technique, marketing, and technology. In recent years, some scholars have found more factors that affect competitive advantage, such as knowledge management, $R \& D$ (research \& developing) capability (Lin, 2003; Kanchanda and Ussahawanitchakit, 2011), international human capital (Wright et al., 2016), home nations and global scope of enterprises (Liang et al., 2012), local partner (Wu et al., 2011), and knowledge transfer (Ajmal and Koskinen, 2010; Oddou et al., 2013) etc.

Moreover, considering the heterogeneity of international HSR projects, some research showed how to improve HSR contractors' competitive advantage, e.g., Liu and Liao (2010) explored how service quality, complaint handling, customer satisfaction affect customer loyalty in Taiwan High-Speed Rail (THSR) Corporation. Sun et al., (2011) compared CRH with Shinkansen in terms of operation management and organizational management and proposed that fare adjustment mechanism and environment protection should be put at the critical position to gain its competitive advantage. Zhang et al. (2019) explored the sources of contractors' competitive advantage on international HSR construction projects and found that technical skills were the most component in the factor system. In addition, HSR project cannot only provide profit to the contractor, but also bring considerable financial revenue to the host country, which gives a higher request to the contractor's sense of social responsibility and ability to deal with trust crisis (Utsunomiya and Hodota, 2011; Zhou et al., 2014; Vickerman, 2018). Therefore, winning an HSR project does not only cover technical and economic issues but is also affected by many other factors including but not limited to marketing, social image, etc.

However, the existing literature is not comprehensive enough, and reasonable theory is not used 
123 Based on the previous TCA research, this paper combined the three theoretical categories (e.g.

\begin{tabular}{|c|c|c|}
\hline Variable code & Variables & Sources \\
\hline V01 & Tender price & Shen et al. (2006); Scheepbouwer et al. (2017) \\
\hline V02 & Financial performance & Green et al. (2008); Oyewobi et al. (2015) \\
\hline V03 & Financial capability & Lu et al. (2008); Huang et al. (2013) \\
\hline V04 & Historical contract non-performance & Obloj and Obloj (2006); \\
\hline V05 & Social responsibility & Du et al. (2010); Velásquez (2012) \\
\hline V06 & Cultural difference & Chan et al. (2004); Shenkar (2012) \\
\hline V07 & Productivity & Cottrell (2006); Helms (2013) \\
\hline V08 & Internationalization & Liang et al. (2012) \\
\hline V09 & Coordination ability & Wu et al. (2011) \\
\hline V10 & Human resources & Lu et al. (2008); Wright et al. (2016) \\
\hline V11 & Services & Tarawne (2014); Harrigan and Diguardo (2017) \\
\hline V12 & Past performance and experience & Shen et al. (2006); Rendon et al. (2015) \\
\hline V13 & Knowledge transfer & Ajmal and Koskinen (2010) \\
\hline V14 & Competitive Intelligence & Wright et al. (2009), Agnihotri and Rapp (2011) \\
\hline V15 & None accident history & San et al. (2010), San and Yoon (2013) \\
\hline V16 & Technology responsiveness & Kamruzzaman and HiroyukiTakeya (2008) \\
\hline V17 & Technology transfer & Glass and Saggi (2010) \\
\hline V18 & Patents \& Innovation & Harrigan and Diguardo (2017) \\
\hline V19 & Eligibility \& international criteria & Zhang (2012), Melykh and Melykh (2016) \\
\hline V20 & Resources integration & Engwall and Jerbrant (2003), Ghapanchi et al. (2014) \\
\hline V21 & Organizational flexibility & Kanchanda and Ussahawanitchakit (2011), Santos-Vijande et al. (2012) \\
\hline V22 & Project maturity & Ghapanchi et al. (2014) \\
\hline V23 & Marketing strategy & Chan et al. (2004), Tan et al. (2011) \\
\hline V24 & Risk management capability & Elahi (2013); Mu et al. (2014) \\
\hline V25 & Localization level & Brentani and Kleinschmidt (2015) \\
\hline
\end{tabular}




\subsection{Overall Research Framework} discussion as illustrated in Fig.1.

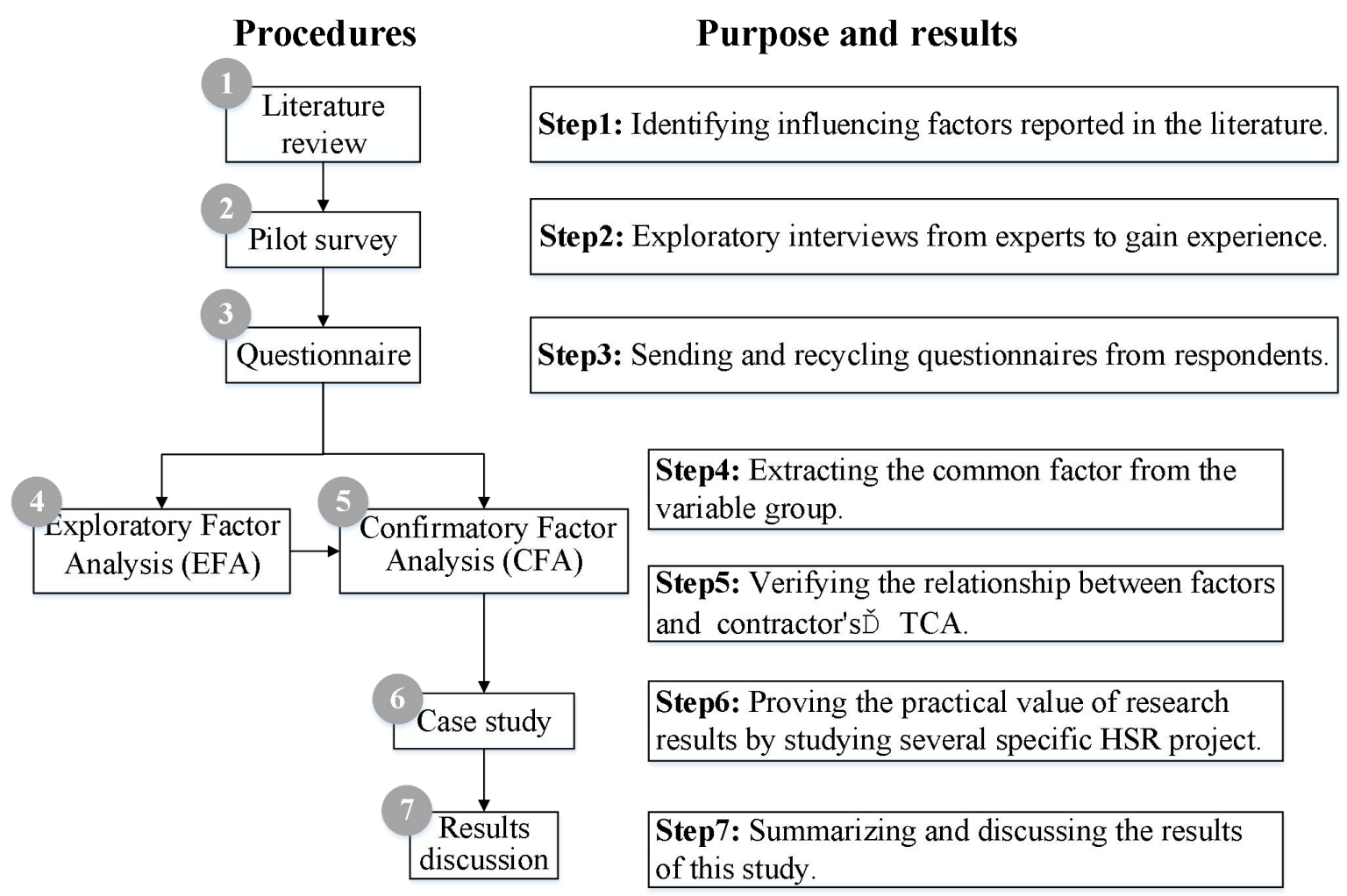

Fig. 1. Conceptual Model of the Study

\subsection{Data Collection}

Prior to comprehensive research, a pilot survey was carried out with ten experts who had more than ten years of HSR project experience to determine whether the pre-defined 25 factors in Table 1 could affect contractors' TCA in the international HSR project. Details about ten respondents are given in Appendix I. Through this process, V25 was removed because it was considered with a high relevance with V06 and V07. By studying the comments and suggestions received from the experts, 
the final list was formed, including 24 reasonable factors to ensure their comprehensiveness and appropriateness of them to represent the TCA of HSR contractors.

Following the pilot study, the questionnaire was designed with two parts. In the first part, the background information of survey participants was asked, such as work experience, and job category, etc. The other part included participants' attitudes towards the impact of 24 factors on the contractors' TCA. A five-point Likert-scale was used to measure their perception of the importance of each variable, ranging from the numerical score of 1 (not important) to 5 (extremely important).

The questionnaire survey was performed during November and December of 2017. A total of 554 questionnaires were distributed through the field and web-based reviews to the professionals with rich experience and knowledge on this issue. 275 responses were returned, representing a response rate of $49.64 \%$. After removing invalid questionnaires that were not answered completely, 256 final usable questionnaires remained, which were suitable and enough for later research. As shown in Table 2, around $81 \%$ of the respondents were project staff with experience in HSR industry, with the remaining being scholars who worked on research in HSR management. The data also indicates that the respondents have extensive knowledge and experience in the field, which strengthened the confidence of the data quality.

Table 2. Background Information of Respondents in the Survey

\begin{tabular}{c|c|c|c|c|c|c|c|c}
\hline \multicolumn{2}{c|}{ Years of Experiences } & $\leqq 5$ & $6-10$ & $11-15$ & $16-20$ & $>20$ & Total & Percentage \\
\hline \multirow{3}{*}{ Academia } & Professor & 0 & 0 & 2 & 3 & 3 & 8 & $3.13 \%$ \\
\cline { 2 - 9 } & Associate Professor & 1 & 8 & 5 & 3 & 1 & 18 & $7.03 \%$ \\
\cline { 2 - 10 } & $\begin{array}{c}\text { Assistant } \\
\text { professor/lecturer }\end{array}$ & 15 & 7 & 0 & 0 & 0 & 22 & $8.59 \%$ \\
\hline \multirow{7}{*}{ Industry } & Senior manager & 12 & 5 & 8 & 6 & 8 & 39 & $15.23 \%$ \\
\cline { 2 - 10 } & Department manager & 2 & 16 & 9 & 7 & 9 & 43 & $16.80 \%$ \\
\cline { 2 - 10 } & Project manager & 5 & 13 & 18 & 6 & 5 & 47 & $18.36 \%$ \\
\cline { 2 - 9 } & Technical supervisor & 6 & 4 & 5 & 3 & 2 & 20 & $7.81 \%$ \\
\hline
\end{tabular}




\begin{tabular}{c|c|c|c|c|c|c|c|c}
\hline & Engineer & 18 & 10 & 4 & 2 & 8 & 42 & $16.41 \%$ \\
\cline { 2 - 9 } & Others & 8 & 3 & 1 & 3 & 2 & 17 & $6.64 \%$ \\
\hline Total & 256 & 67 & 66 & 52 & 33 & 38 & 256 & $100 \%$ \\
\hline Percentage & $100 \%$ & $26.17 \%$ & $25.78 \%$ & $20.31 \%$ & $12.89 \%$ & $14.84 \%$ & - & - \\
\hline
\end{tabular}

157

\subsection{Factor Analysis}

In this paper, EFA is usually performed to reveal potential factor mechanism and to construct theoretical system, especially to extract the common factor from the variable group as well as to explain the complex interactions of different variables. But it has been criticized for its data-driven and subjective nature. Therefore, to ensure the accuracy of the model, CFA is often performed to test the hypothetical factor system. In this paper, EFA is used to analyze data from practitioners who had more than five years of experience to explore the potential factor system, based on the assumption that more experienced practitioners are more likely to provide more effective information. Afterwards, CFA was performed to test the factor mechanism revealed by EFA. In this way, EFA provides a theoretical basis for CFA, and CFA validates and corrects the results of EFA, which helps to build an unbiased framework model (Chen et al., 2012).

\section{Empirical Results}

\subsection{Exploratory Factor Analysis (EFA)}

EFA was performed by SPSS23.0 using the questionnaire data from 189 respondents with over five years of experience. According to Maccallum et al. (2001), when determining whether a data set can be done with EFA, two main conditions must be met, namely the sample size and the degree of correlation of the variables. Specifically, the sample size selected in EFA should be at least five times the number of variables, to ensure the accuracy of the research (Floyd and Widaman, 1995). This paper selected 196 samples and 24 variables, with a ratio of over 8:1 meeting the requirement. 
176 Secondly, the results of the Kaiser-Meyer-Olkin (KMO) and Bartlett's test must ensure that the 177 initial variables are strongly correlated (Deng et al., 2014b). In this research, the 178 Kaiser-Meyer-Olkin index was 0.866 higher than the minimum value at 0.8 , indicating that the 179 correlation between variables was satisfactory. The Bartlett's test $\left(\chi^{2}=2662.81, d f=276\right.$, sig. $\left.=0.00\right)$ 180 suggested that the data were suitable for EFA. Besides, the communality values over 0.50 , the 181 corrected item-total correlations higher than 0.30 , and the Cronbach alpha values for the final six 182 factors over 0.70 indicated that each extracted element was internally consistent and reliable.

183 As revealed in Table 3, six factors could be extracted by merging variables with relatively higher 184 factor loads, which accounted for $71.53 \%(>60 \%)$ of the total variance. According to Joliffe and 185 Morgan (1992), a variable with a factor load below 0.45 should be considered as a weak index 186 element and should be removed from the whole indicator system. In this study, all the factor loads 187 ranged from 0.664 to 0.905 , suggesting the reliability of all variables in this indicator system. Then, 188 six common factors were renamed according to their common characteristics of the variables with 189 relatively higher loads. They were experience-mining advantage (F1), funding strategy (F2), 190 organizational management $(\mathrm{F} 3)$, technical resource $(\mathrm{F} 4)$, risk-controlling performance $(\mathrm{F} 5)$, and 191 social image (F6). 
Table 3. Factor Load Matrix after Rotation and the Extracted Common Factors

\begin{tabular}{|c|c|c|c|c|c|c|c|c|c|c|}
\hline \multirow[b]{2}{*}{ Variables } & \multirow{2}{*}{$\begin{array}{l}\text { Mean } \\
\text { Value }\end{array}$} & \multirow[b]{2}{*}{ Rank } & \multirow[b]{2}{*}{ Communalities } & \multirow{2}{*}{$\begin{array}{l}\text { Item-Total } \\
\text { Correlation }\end{array}$} & \multicolumn{6}{|c|}{ Factor load matrix * } \\
\hline & & & & & 1 & 2 & 3 & 4 & 5 & 6 \\
\hline Coordination ability & 3.58 & 14 & 0.700 & 0.564 & 0.888 & & & & & \\
\hline $\begin{array}{c}\text { Past performance and } \\
\text { experience }\end{array}$ & 3.59 & 13 & 0.794 & 0.655 & 0.840 & & & & & \\
\hline Knowledge transfer & 3.56 & 17 & 0.725 & 0.558 & 0.830 & & & & & \\
\hline Human resources & 3.60 & 12 & 0.840 & 0.636 & 0.813 & & & & & \\
\hline Services & 3.80 & 4 & 0.631 & 0.448 & 0.777 & & & & & \\
\hline Competitive Intelligence & 3.63 & 11 & 0.638 & 0.583 & 0.723 & & & & & \\
\hline Internationalization & 3.36 & 24 & 0.515 & 0.481 & 0.664 & & & & & \\
\hline Tender price & 3.81 & 3 & 0.796 & 0.530 & & 0.861 & & & & \\
\hline Financial capability & 3.69 & 7 & 0.734 & 0.481 & & 0.821 & & & & \\
\hline Productivity & 3.64 & 10 & 0.708 & 0.530 & & 0.787 & & & & \\
\hline Financial performance & 3.88 & 1 & 0.721 & 0.563 & & 0.782 & & & & \\
\hline Resources integration & 3.55 & 19 & 0.722 & 0.477 & & & 0.813 & & & \\
\hline Organizational flexibility & 3.47 & 20 & 0.717 & 0.521 & & & 0.754 & & & \\
\hline Marketing strategy & 3.57 & 16 & 0.577 & 0.396 & & & 0.732 & & & \\
\hline Project maturity & 3.58 & 14 & 0.575 & 0.390 & & & 0.730 & & & \\
\hline $\begin{array}{l}\text { Eligibility \& } \\
\text { international criteria }\end{array}$ & 3.65 & 9 & 0.516 & 0.332 & & & 0.669 & & & \\
\hline Patents \& Innovation & 3.74 & 6 & 0.878 & 0.483 & & & & 0.905 & & \\
\hline Technical responsiveness & 3.75 & 5 & 0.852 & 0.490 & & & & 0.875 & & \\
\hline Technology transfer & 3.84 & 2 & 0.838 & 0.537 & & & & 0.846 & & \\
\hline Risk management capability & 3.46 & 21 & 0.625 & 0.329 & & & & & 0.773 & \\
\hline $\begin{array}{l}\text { Historical contract } \\
\text { non-performance }\end{array}$ & 3.56 & 17 & 0.674 & 0.410 & & & & & 0.771 & \\
\hline None accident history & 3.67 & 8 & 0.670 & 0.450 & & & & & 0.754 & \\
\hline Social responsibility & 3.44 & 22 & 0.863 & 0.411 & & & & & & 0.888 \\
\hline Cultural difference & 3.41 & 23 & 0.861 & 0.414 & & & & & & 0.882 \\
\hline \multicolumn{5}{|c|}{ Cronbach alpha } & 0.916 & 0.876 & 0.825 & 0.916 & 0.734 & 0.849 \\
\hline \multicolumn{5}{|c|}{ Eigenvalues } & 7.288 & 2.954 & 2.401 & 1.704 & 1.503 & 1.318 \\
\hline \multicolumn{5}{|c|}{ Variance $(\%)$} & 19.636 & 12.740 & 12.563 & 10.749 & 8.548 & 7.297 \\
\hline \multicolumn{5}{|c|}{ Cumulative variance $(\%)$} & 19.636 & 32.376 & 44.939 & 55.688 & 64.237 & 71.533 \\
\hline \multicolumn{5}{|c|}{ Kaiser-Meyer-Olkin measure of sampling adequacy } & \multicolumn{6}{|c|}{0.866} \\
\hline \multirow{3}{*}{\multicolumn{2}{|c|}{ Bartlett's test of sphericity }} & \multicolumn{3}{|c|}{ Approximate $\chi^{2}$} & \multicolumn{6}{|c|}{2662.81} \\
\hline & & \multicolumn{3}{|c|}{$d f$} & \multicolumn{6}{|c|}{276} \\
\hline & & \multicolumn{3}{|c|}{ Significant } & \multicolumn{6}{|c|}{0.000} \\
\hline
\end{tabular}




\subsection{Confirmatory Factor Analysis (CFA)}

This research initially established an indicator system that affects contractors' TCA in

197 international HSR projects, including 6 grade I indexes and 24 grade II indexes. Since the grade I index is a general indicator and cannot be measured directly, it is called a latent variable. Grade II index can be measured directly and is named the observable variable. model has good convergent validity. Then a second-order CFA model was built and estimated parameters by maximum likelihood (ML). The ML method was used because it provided an projects. Fig. 2 demonstrates the second-order CFA model integrating the measurement model and the structural model. Also, to evaluate the fitness of the overall model, all parameters in the 4), meaning that the sample size met the requirements.

Following the collected data, six common factors were linked to contractors' TCA in HSR proposed model must be successfully estimated. Alzahrani and Emsley (2013) suggested that the integrated model could be evaluated by a series of statistical fitness indices. Specifically, the model should meet the standards for absolute fit, incremental fit, and parsimonious fit. After validation, the goodness of fit of the initial model is shown in Table 4. All indices complied with the recommended standards, indicating that the second-order CFA model can be deemed suitable. 


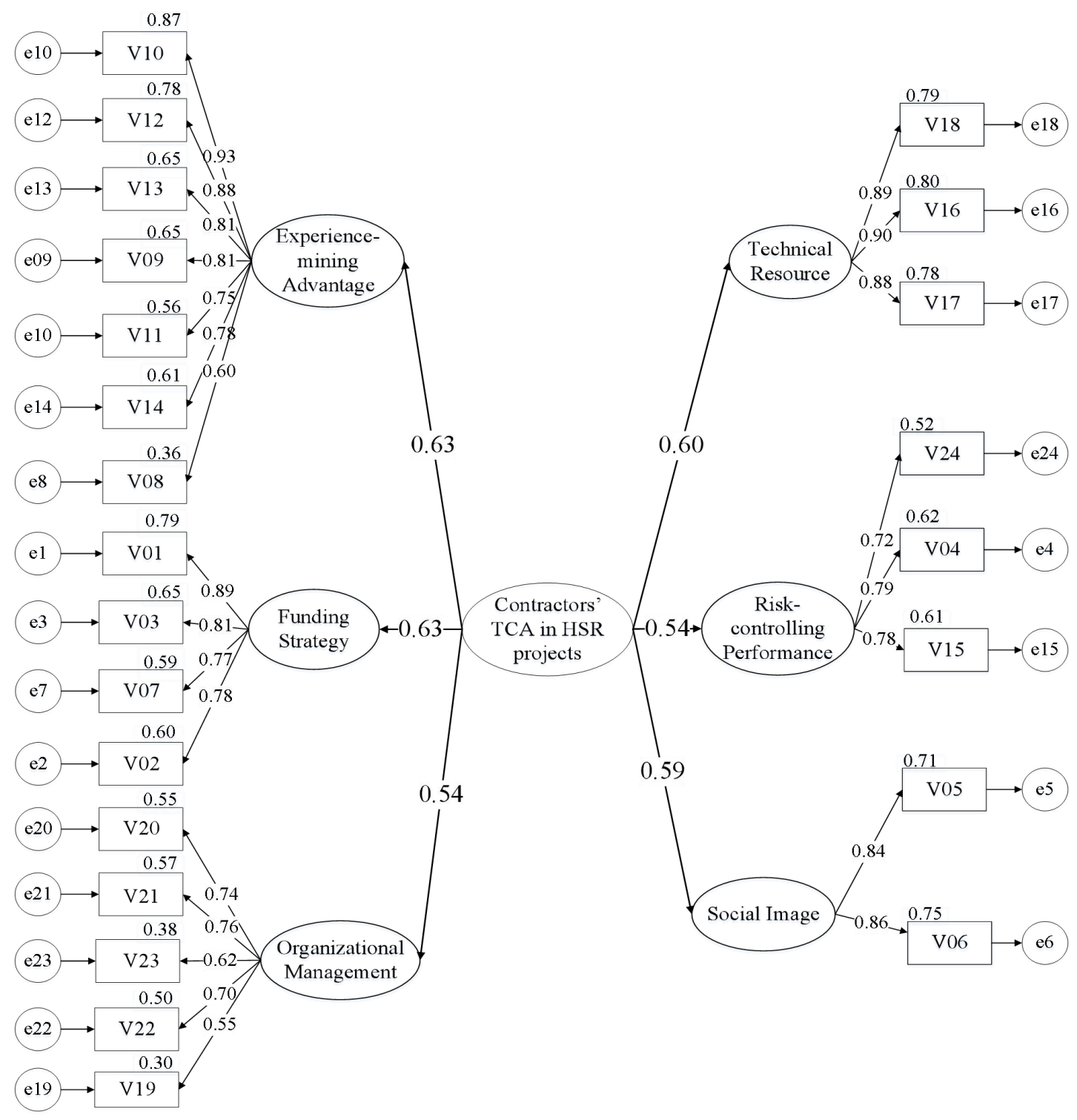

Fig. 2. Second-order CFA Model

219 The analysis of path coefficients estimates the effects of variables in a causal system based on a

220 structural equation. In the current model, all latent variables were related to the TCA of contractors

221 in HSR projects, but their path coefficients differed. Table 5 lists the path coefficients of the six

222 latent variables in the optimized structural equation model in descending order. The final

223 second-order CFA model revealed that three latent variables, i.e., experience-mining advantage,

224 funding strategy, and technical resource had the highest weights, with relative importance at $18.18 \%$, 
Table 4. The Goodness of Fit of the Second-order CFA Model

\begin{tabular}{|c|c|c|c|c|}
\hline Type & Index & Fit standard of fitness & Value & Result \\
\hline \multirow{5}{*}{ Absolute fit } & $\chi^{2}$ test & $>0.05$, good fit & 0.051 & $\sqrt{ }$ \\
\hline & $\mathrm{CMIN} / \mathrm{DF}$ & $<2$, good fit & 1.152 & $\sqrt{ }$ \\
\hline & RMR & $<0.05$, good fit & 0.044 & $\sqrt{ }$ \\
\hline & RMSEA & $<0.08$, not bad fit; $<0.05$, good fit & 0.024 & $\sqrt{ }$ \\
\hline & GFI & $>0.90$, good fit & 0.918 & $\sqrt{ }$ \\
\hline \multirow[t]{5}{*}{ Incremental fit } & NFI & $>0.90$, good fit & 0.923 & $\sqrt{ }$ \\
\hline & RFI & $>0.90$, good fit & 0.914 & $\sqrt{ }$ \\
\hline & IFI & $>0.90$, good fit & 0.989 & $\sqrt{ }$ \\
\hline & TLI & $>0.90$, good fit & 0.988 & $\sqrt{ }$ \\
\hline & CFI & $>0.90$, good fit & 0.989 & $\sqrt{ }$ \\
\hline \multirow[t]{3}{*}{ Parsimonious fit } & PGFI & $>0.50$, good fit & 0.753 & $\sqrt{ }$ \\
\hline & PNFI & $>0.50$, good fit & 0.823 & $\sqrt{ }$ \\
\hline & PCFI & $>0.50$, good fit & 0.882 & $\sqrt{ }$ \\
\hline
\end{tabular}

Table 5. Results of Direct Path Coefficient and Weights of Relative Importance

\begin{tabular}{l|c|c|c|c}
\hline Relationship & $\begin{array}{c}\text { Direct path } \\
\text { coefficient }\end{array}$ & $\mathrm{p}$-Value & Statistical results & $\begin{array}{c}\text { Weights of relative } \\
\text { importance (\%) }\end{array}$ \\
\hline F1: Experience-mining Advantage $\rightarrow$ TCA & 0.636 & $<0.001$ & Accepted & $18.18 \%$ \\
\hline F2: Funding Strategy $\rightarrow$ TCA & 0.631 & $<0.001$ & Accepted & $17.90 \%$ \\
\hline F4: Technical Resource $\rightarrow$ TCA & 0.600 & $<0.001$ & Accepted & $14.77 \%$ \\
\hline F6: Social Image $\rightarrow$ TCA & 0.590 & $<0.001$ & Accepted & $17.05 \%$ \\
\hline F5: Risk-controlling Performance $\rightarrow$ TCA & 0.543 & $<0.001$ & Accepted & $15.34 \%$ \\
\hline F3: Organizational Management $\rightarrow$ TCA & 0.521 & $<0.001$ & Accepted & $16.76 \%$ \\
\hline
\end{tabular}

\section{Discussion}

\subsection{Six Components}

\subsubsection{Experience-mining Advantage}

233 The first component is named as experience-mining advantage, which was the most significant factor of contractors' TCA. Experience mining means that the company collects instances of past 
experiences as well as useful knowledge from consortium members, and stores them in the experience database for use, making themselves more competitive in the HSR market (Linden et al., 2009; Shen et al., 2013). It was described by seven sub-criteria, among which the more important factors included: coordination ability (weight of relative importance at $16.76 \%$ ), past performance and experience (15.86\%), and knowledge transfer (14.57\%). Since HSR project is a complex, large-scale system involving many industries, contractors with rich experience would be more likely to identify potential management or technical problems by experience mining, which would become a significant advantage in the competition.

This component is often reflected in several levels: (1) coordination experience mining with consortium members. The joint venture is usually initiated by the core enterprise, enhancing TCA resource that difficult to imitate together to help the alliance deal with the uncertain environment and reposition itself in the dynamic market (Wu et al. 2011); (2) the construction experience mining of similar projects. Experienced contractors tend to have more experienced employees and relevant experts who will help enhance organizational management capabilities and ensure adequate and sustainable cash flow (Shen et al., 2006). The contractors can also learn from failure so that this doesn't happen again, thus helping to achieve success later (Doloi et al., 2011); (3) integration experience mining of various resources. As the market shifts faster and the product life cycle becomes shorter, how can the bidders use external resources to coordinate the members to achieve a common goal has become the key (Lu et al. 2008). In short, the experience-mining advantage is a 
comprehensive evaluation of the contractor's ability to utilize past project experience, including previous operating conditions and coordination capabilities, which can be directly used to measure the subsistence and development of contractors.

\subsubsection{Funding Strategy}

260 Funding strategy showed a path coefficient of 0.631 , with a proportion of $17.90 \%$. The three most 261 significant factors included tender price (27.38\%), financial capability $(24.92 \%)$, and financial 262 performance $(24.00 \%)$. Funding strategy refers to the most proper project quotation and financing means adopted by the contractor for opening up market, based on the accurate calculation of costs and full estimation of competitors' quotation strategies (Shen et al., 2006; Huang et al., 2013). The tender price provided by the contractors is an important source of TCA, which mainly comes from two aspects, cost leadership and reasonable/reasonable pricing. The contractor's TCA can be established to obtain greater benefits at the same cost or to obtain the same benefits at a lower cost. Besides, compared to usual international projects, the proportion of financing in HSR is much higher because of greater capital investment, longer investment recovery cycle, and more significant scale economies effect (Utsunomiya and Hodota, 2011). Therefore, clients are more inclined to choose the contractor with stronger financing capability. For example, Thailand's "Rice for HSR" program with China demonstrated the diversity and flexibility of financing methods in HSR projects. Financial performance is also one of the important indicators for evaluating bidders, which

274 indirectly reflects its project management capability to ensure the economic sustainability of the project during its construction. 


\subsubsection{Technical Resource}

Technical resource also exerted an important influence on the contractors' TCA of international HSR projects $(17.05 \%)$, including technical responsiveness $(33.71 \%)$, patents \& innovation (33.33\%), and technology transfer (32.96\%). Most HSR tender documents contain technical response documents, with the degree of response and deviation descriptions for each engineering component. Generally, the higher the technical responsiveness of a contractor would lead to a greater chance of winning the project. Therefore, contractors should identify and understand the customer's needs and develop a "personalized but cost-effective response plan". In addition, R\&D (i.e., research \& development) innovation and technology transfer are also important drivers for technical advantage. Innovation includes original innovation, integration innovation and significant (Weerawardena and Mavondo, 2011). In brief, contractors should flexibly re-adjust technology according to market variations, and create greater value for customers based on maintaining the original technology leadership (Lin, 2003). Only in this way can contractors convert their accumulated technique advantage into TCA, and further increase the chance of winning the project.

\subsubsection{Social Image}

293 Social image was responsible for $16.76 \%$ of the total variances. It consists of the variables, 294 namely social responsibility (49.41\%) and cultural difference (50.59\%). Social image dynamically shows the relationship between contractors and other stakeholders in the social environment with 
one hand, if contractors have to maintain a positive social reputation to maintain their competitive advantage in the HSR market (Du et al., 2010). On the other hand, the smaller cultural differences between the country where the project is located and its host country, the more likely that the contractor could win the project. For example, Spanish has brought the similar culture to Latin America because of the long colonial history in the eighteenth century, so the Spanish National Railways took an active part in the competition for HSR project in Brazil and Mexico. Hence, the good social image that the contractors have accumulated and the similarity of the culture to the host country will become their TCA.

\subsubsection{Risk-controlling Performance}


participate in the bidding, which made $\mathrm{CRH}$ and several European contractors who had major safety

319 accident unable to participate in the bid.

\subsubsection{Organizational Management}

Organizational management accounted for the smallest proportion of the whole variances (14.77\%). The three most significant factors are organization flexibility $(22.62 \%)$, resources integration (21.73\%), project maturity (21.13\%). In terms of HSR enterprise, effective organizational management policies help them provide products and services that satisfy customers, thereby gaining more value and winning sustainable competitive advantage in the market (Wen and Qiang, 2016). Besides, since the HSR project is in an uncertain and dynamic competitive surrounding context, flexible project organization can help them adapt to the environment quickly and minimize the effect of external uncertainty to maintain the dynamic matching between the organization and the environment (Vogel and Güttel, 2013). Temporary management advantage is also reflected in the contractor's planning and implementation capabilities for project quality, schedule, and cost objectives.

\subsection{In-depth Discussion of Components}

Primarily, the six components may be broadly sorted into two dimensions, as shown in Fig. 3. basis of enterprises), organizational management (the operation process of enterprises), and TCA in the corporation dimension is developed from the perspective of construction enterprises, which is heterogeneous and irreplaceable in different companies. To concluded, the formation of TCA from the corporation dimension is mainly attributed to the technical resource (the operation experience-mining advantage (the operation performance of enterprises), which are accumulated 
from corporate operations and project practices for decades. TCA in the project dimension is determined by market behaviors taken by contractors according to different market structures and environment in the particular project. To win the HSR project, contractors must utilize local resources and adopt suitable competitive strategies, including their social image (the competition basis of projects), funding strategy (the competition strategy of projects), and risk-controlling performance (the operation performance of projects). Coincidentally, TCA in the corporation and project dimensions both accounted for $50 \%$ of the overall factors as shown in Table 6 . However, scholars' research on competitive advantage often focused on only one aspect, with some concentrating on the inherent advantages of enterprises (Melykh and Melykh, 2016), while others are focusing on external markets (Liang, 2012). The two aspects are mutually reinforcing and equally crucial for international HSR contractors.

These six components could be further divided into three categories, namely action-based TCA, resource-based TCA, and performance-based TCA, as shown in Fig. 3. As displayed in Table 6, resource-based TCA plays a slightly more significant role compared to another two categories, which included technical resources from corporation and social image from project. Technical strength is the core layer of the HSR industry, playing a decisive role in the competitive market. However, technical resources are easily imitated or replaced because the diffusion of technique throughout the whole HSR industry is very rapid (Lin, 2003). Therefore, if contractors want to maintain a leading technical position, they must continue to carry out technological innovation (Weerawardena and Mavondo, 2011). In terms of social image, another important part of the contractor's resource advantage, it helps build a social network that exists outside the contractors 
and is conducive to the acquisition of external resources. This social effect is more obvious in Asia,

361 because partners in Asian countries tend to connect with each other through social and ethnic networks (Utsunomiya and Hodota, 2011).

Table 6. Weight of Each Component in the TCA Theory

\begin{tabular}{c|c|c|c|c|c|c}
\hline Contractors' TCA & Weight & $\begin{array}{c}\text { Corporation } \\
\text { dimension }\end{array}$ & $\begin{array}{c}\text { Project } \\
\text { dimension }\end{array}$ & $\begin{array}{c}\text { Action-based } \\
\text { TCA }\end{array}$ & $\begin{array}{c}\text { Resource-based } \\
\text { TCA }\end{array}$ & $\begin{array}{c}\text { Performance-based } \\
\text { TCA }\end{array}$ \\
\hline F1: Experience-mining Advantage & 0.1818 & $\sqrt{ }$ & & & & $\sqrt{ }$ \\
\hline F2: Funding Strategy & 0.1790 & & $\sqrt{ }$ & $\sqrt{ }$ & \\
\hline F4: Technical Resource & 0.1705 & $\sqrt{ }$ & & & $\sqrt{ }$ & \\
\hline F6: Social Image & 0.1676 & & $\sqrt{ }$ & & $\sqrt{ }$ \\
\hline F5: Risk-controlling Performance & 0.1534 & & $\sqrt{ }$ & & $\sqrt{ }$ \\
\hline F3: Organizational Management & 0.1477 & $\sqrt{ }$ & & $\sqrt{ }$ & \\
\hline Total Weight & 1.0000 & 0.5000 & 0.5000 & 0.3267 & 0.3381 & 0.3352 \\
\hline
\end{tabular}

\begin{tabular}{|c|c|c|c|c|}
\hline & & Resource-based & Action-based & Performance-based \\
\hline Corporation-based & F4 & Technical Resource & F3 Organizational Management & F1 Experience-mining Advantage \\
\hline Project-based & F6 & Social Image & Funding Strategy & F5 Risk-controlling Performance \\
\hline
\end{tabular}

Fig. 3. Two Classifications of Six Components

Performance-based TCA accounted for $33.52 \%$ of the whole factors, including experience-mining advantage and risk-controlling performance. Experience-mining advantage is based on the past performance of contractors, which contains coordination experience with consortium members, construction experience of similar projects, and integration experience using various resources. HSR project clients tend to choose experienced contractors who have better operational performance and the ability to work with consortium members. Also, clients are more inclined to choose bidders that can handle risks better than competitors, or that can enter the market with both high risks and high return while other rivals hesitate to enter. 
375 (weight: $32.67 \%$ ), included organizational management and funding strategy. In hypercompetitive dynamic HSR markets, contractors should maintain persistent information flow to predict rivals' behavior, manage their organizations rationally, and adopt appropriate competitive strategies (Chan et al., 2004). Organizational management refers to the actions for enterprises to integrate internal and external resources to maximize the interests (Kanchanda and Ussahawanitchakit, 2011).

380 Nowadays, some excellent enterprises often cultivate their dynamic capabilities by innovating organization forms and improving management functions to gain new competitive advantages. Funding strategy is another important indicator for judging contractors' TCA in this dimension. If HSR contractor can provide a lower offer according to the specific circumstance of the project, with a lower interest rate and higher amount of loans without guarantees, they will be more likely to win the bid. Conversely, if the competitor is unable to meet the financing requirements, it may not even be eligible for competition.

\section{Case Study}

\subsection{Case Background}

In recent years, China High-speed Railway (CRH), Canadian Bombardier (LRC), German Siemens (ICE), and French Alstom (TGV) are the major four HSR systems in the global market,

391 which accounts for almost half of the total market share. Shinkansen (Japan) has a slightly lower

392 share than the four systems but in a very important position in the Asian HSR market. China and 
on many typical international HSR projects (Utsunomiya and Hodota, 2011). Therefore, this study uses competitions between CRH (China) and Shinkansen (Japan) in two HSR projects as examples.

In order to assess their TCA in the corporation dimension, each of the 15 variables was given a detailed evaluation criterion. Then questionnaires related to variables were designed and distributed to 10 respondents who had over 10 years of working experience in HSR companies, and relevant details about ten respondents are given in Appendix I. Each variable was set on a scale of 1 to 5, with 5 being the best TCA. For example, the variable "services" was defined as "the whole project proposal, including design, manufacturing, construction, after-sale, and staff-training." If the contractor provides fairly good after-sales supporting services, the value of this variable maybe 5 . On the contrary, the variable may take the value 1 .

Table 7 shows the factor scores of $\mathrm{CRH}$ and Shinkansen in the corporation dimension. From the perspective of technical resources, $\mathrm{CRH}$ (4.565) takes the leading position compared with Shinkansen (4.183). This is due to the core technologies of CRH such as engineering construction and system joint debugging, as well as "introduction, absorption, then innovation" HSR strategy taken by China. As for experience-mining advantage and organizational management, Shinkansen is better than $\mathrm{CRH}$, which is owing to its long operating history and rich experience. Overall, Shinkansen (2.212) had a slightly higher score than CRH (2.132) in the corporation dimension. Japan has the first HSR in the world, with traditional advantages in operating history, project management, post-maintenance, and technology upgrading, which makes Shinkansen enjoy a high reputation in the world. 
Table 7. Factor Scores of CRH and Shinkansen in the Corporation Dimension

\begin{tabular}{c|c|c|c}
\hline Contractors' TCA in the corporation dimension & CRH (China) & Shinkansen (Japan) & Weight \\
\hline Technical Resource & 4.565 & 4.183 & 0.1705 \\
\hline Organizational Management & 4.112 & 4.376 & 0.1477 \\
\hline Experience-mining Advantage & 4.107 & 4.688 & 0.1818 \\
\hline Total Score & 2.132 & 2.212 & - \\
\hline
\end{tabular}

\subsection{Data Analysis and Results}

In this part, two representative projects (e.g. Jakarta-Bandung high-speed railway in Malaysia and

Mumbai-Ahmedabad high-speed railway in India) were selected to show the competitions between

$\mathrm{CRH}$ (China) and Shinkansen (Japan). These two high-speed railways both had attracted

different. Jakarta-Bandung high-speed railway has been contacted to Chinese contractors, while the

Mumbai-Ahmedabad high-speed railway was contracted and constructed by Japanese contractors.

Table 8 and Fig. 4 illustrates the factor scores of CRH and Shinkansen in the project dimension by different forms.

Concerning Jakarta-Bandung high-speed railway, $\mathrm{CRH}$ is better than Shinkansen in two aspects:

funding strategy and risk-controlling performance, but a litter lower in social image. After adding the total score of two dimensions together, CRH earns a score of 4.287, higher than Shinkansen's 4.116. And the success of CRH largely attributed to excellent funding strategy and risk management capability. China provided a loan condition that was more in line with Indonesia's national conditions without government funding and any guarantee from the government, which became their key success factor. strategy and social image, but slightly lower in risk-controlling performance. After summing up the 
434 factor scores of two dimensions, 4.088 earned by $\mathrm{CRH}$ is lower than 4.263 from Shinkansen, 435 suggesting the leading position of Shinkansen in the project. It is worth mentioning that Shinkansen had taken proper funding strategy in the competition, a total loan of approximately 190 billion yen was provided, the annual interest rate was reduced to $0.1 \%$ and the repayment period was extended successful bidder.

440

Table 8. Factor Scores of CRH and Shinkansen in the Project Dimension

\begin{tabular}{|c|c|c|c|c|c|c|}
\hline \multirow{2}{*}{$\begin{array}{l}\text { Contractors' TCA in the } \\
\text { project dimension }\end{array}$} & \multicolumn{3}{|c|}{ Jakarta-Bandung high-speed railway (Malaysia) } & \multicolumn{3}{|c|}{ Mumbai-Ahmedabad high-speed railway (India) } \\
\hline & CRH (China) & Shinkansen (Japan) & Weight & CRH (China) & Shinkansen (Japan) & Weight \\
\hline Funding Strategy & 4.686 & 3.663 & 0.1790 & 3.767 & 4.369 & 0.1790 \\
\hline Social Image & 3.925 & 4.136 & 0.1676 & 3.728 & 4.162 & 0.1676 \\
\hline Risk-controlling Performance & 4.295 & 3.617 & 0.1534 & 4.284 & 3.725 & 0.1534 \\
\hline Total Score & 2.155 & 1.904 & & 1.956 & 2.051 & \\
\hline $\begin{array}{l}\text { Experience } \\
\text { Advantage }\end{array}$ & al Image & $\begin{array}{l}\text { Risk- } \\
\text { ntrolli... } \\
\text { H (China) } \\
\text { nkansen (Japan) }\end{array}$ & & $\begin{array}{l}\text { Funding } \\
\text { Strategy }\end{array}$ & Resource & (Japan) \\
\hline
\end{tabular}

442 (a)

(b)

Fig. 4. Factor Scores of CRH and Shinkansen: (a) Jakarta-Bandung high-speed railway, (b)

\section{Conclusions}


development and application of relevant theoretical research. Prior studies mainly focus on industry-level and firm-level TCA, contractors' TCA in the project dimension has been overlooked.

If international HSR contractors want to stand out in a complex and ever-changing competitive environment, it is not enough to maintain competitive advantage only through experience accumulation and daily operation management. They should also adopt appropriate competition strategies based on fully coordinating resources to form their TCA according to market conditions in the host country and characteristics of other competitors. This paper created the final factors framework by previous literature and pilot survey, and explained how factors affect contractors' TCA in terms of resource, action, and performance, which contributes to the theoretical framework for TCA theory. common factors identified by EFA are experience-mining advantage, funding strategy, organizational management, technical resource, risk-controlling performance, and social image. (2) experience-mining advantage outweighed funding strategy or technical resource as the most important component according to CFA. Then six components were discussed in the perspectives of corporation and project dimensions, action-based, resource-based, and performance-based 464 dimensions. The results revealed that resource-based TCA accounted for the largest proportion, 465 followed by performance-based TCA, and action-based TCA. Finally, the competitions between CRH (China) and Shinkansen (Japan) in two international HSR projects were used as the examples 
contractors' TCA for future application.

Despite the achievement of the objectives, there are still several limitations to this paper. Since only a small number of experts and cases were utilized in the validation of the suggested model, it may not be applied completely to actual decisions. The interrelationships between factors and their influence mechanism on TCA are not analyzed in depth. Given this, further work will be conducted to be more in-depth and practical on this issue. At first, the cause and effect relationships among the underlying factors should be clarified in the future, which will be conducive for HSR contractors to integrate optimal resources based on joint venture experience and take the most effective actions to improve their TCA. Meanwhile, a more comprehensive approach should be developed to explore the best cooperation mode of all members in the consortium, which will help contractors occupy a rather favorable competitive position in the bidding. Another direction for future research is to develop big data methods (e.g., web crawling and text mining) to help HSR contractors dynamically assess their TCA and make real-time strategic decisions in the competition.

\section{Acknowledgments}

The study was financed by the National Natural Science Foundation of China (Grant No.71771052). The authors thank the respondents from both the industry and academia who have assisted the research by completing the interviews or questionnaires about contractors' TCA in the competition of international HSR projects. 


\section{Appendix I. Features of ten respondents}

\begin{tabular}{l|l|l|l}
\hline Respondents & Company type & Positions & Relevant work experience \\
\hline Respondent \#1 & State railway administration & Section chief & 21 years \\
\hline Respondent \#2 & State railway administration & Section chief & 18 years \\
\hline Respondent \#3 & Train manufacturing company & Vice president & 22 years \\
\hline Respondent \#4 & Design and research institute & Deputy director & 17 years \\
\hline Respondent \#5 & $\begin{array}{l}\text { Engineering consultancy services } \\
\text { company }\end{array}$ & Senior engineer & 15 years \\
\hline Respondent \#6 & Management consulting company & Chartered financial analyst & 12 years \\
\hline Respondent \#7 & $\begin{array}{l}\text { International project contracting } \\
\text { company }\end{array}$ & Senior engineer & 25 years \\
\hline Respondent \#8 & General contractor & Project manager & 15 years \\
\hline Respondent \#9 & Civil construction contractor & Project manager & 18 years \\
\hline Respondent \#10 & HSR operator & Project coordinator & 12 years \\
\hline
\end{tabular}

\section{References}

Agnihotri, R., and Rapp, A. (2011). "Perspectives on competitive intelligence within business: A tactical tool for sales-people to gain a competitive advantage.” The Marketing Review, Vol. 11, No. 4, pp. 363-380. DOI: 10.1362/146934711x13210328715948.

Ajmal, M. M, Koskinen, K. U. (2010) "Knowledge transfer in project-based organizations: An organizational culture perspective." Project Management Journal, Vol. 39, No. 1, pp. 7-15. DOI: 10.1002/pmj.20031.

Alzahrani, J. I., and Emsley, M. W. (2013). “The impact of contractors' attributes on construction project success: a post construction evaluation.” International Journal of Project Management, Vol. 31, No. 2, pp. 313-322. DOI: 10.1016/j.ijproman.2012.06.006.

Brentani, U. D., and Kleinschmidt, E. J. (2015). "The impact of company resources and capabilities on global new product program performance.” Project Management Journal, Vol. 46, No. 1, pp. 12-29. DOI: 10.1002/pmj.21470.

Chan, L. L. M., Shaffer, M. A., and Snape, E. (2004). "In search of sustained competitive advantage: the impact of organizational culture, competitive strategy and human resource management practices on firm performance." International Journal of Human Resource Management, Vol. 15, No. 1, pp. 17-35. DOI: 10.1080/0958519032000157320.

Chen, S. F., Wang, S., and Chen, C. Y. (2012). "A simulation study using EFA and CFA programs based the impact of missing data on test dimensionality.” Expert Systems with Applications, Vol. 39, No.4, pp. 4026-4031. DOI: 10.1016/j.eswa.2011.09.085.

Cottrell, D. S. (2006). “Contractor Process Improvement for Enhancing Construction Productivity." Journal of Construction Engineering \& Management, Vol. 132, No. 2, pp. 189-196. DOI: 10.1061/(ASCE)0733-9364(2006)132:2(189).

D'Aveni, R. A., Dagnino, G. B., and Smith, K. G. (2010). “The age of temporary advantage.” Strategic Management Journal, Vol. 31, No. 13, pp. 1371-1385. DOI: 10.1002/smj.897.

Deng, X., Low, S. P., Li, Q., and Zhao, X. (2014a). "Developing competitive advantages in political risk management for international construction enterprises." Journal of Construction Engineering and Management, Vol. 140, No. 9, pp.1-10. DOI: 10.1061/(ASCE)CO.1943-7862.0000836.

Deng, X., Low, S. P., and Zhao, X. (2014b). "Project system vulnerability to political risks in international construction projects: the case of Chinese contractors." Project Management Journal, Vol. 45, No. 2, pp. 20-33. DOI: 10.1002/pmj.21397. 
Derfus, P. J., Maggitti, P. G., Grimm, C. M., and Smith, K. G. (2008). "The red queen effect: competitive actions and firm performance.” Academy of Management Journal, Vol. 51, No.1, pp. 61-80. DOI: 10.2307/20159494.

Doloi, H., Iyer, K. C., Sawhney, A. (2011). "Structural equation model for assessing impacts of contractor's performance on project success.” International Journal of Project Management, Vol. 29, No. 6, pp. 687-695. DOI: 10.1016/j.ijproman.2010.05.007.

Du, S., Bhattacharya, C. B., and Sen, S. (2011). "Corporate social responsibility and competitive advantage: Overcoming the trust barrier." Management Science, Vol. 57, No. 9, pp. 1528-1545. DOI: 10.1287/mnsc.1110.1403.

Elahi, E. (2013). "Risk management: the next source of competitive advantage." Foresight, Vo. 15, No. 2, pp. 117-131. DOI: $10.1108 / 14636681311321121$.

Engwall, M., and Jerbrant, A. (2003). "The resource allocation syndrome: the prime challenge of multi-project management?" International Journal of Project Management, Vol. 21, No. 6, pp. 403-409. DOI: 10.1016/s0263-7863(02)00113-8.

Ghapanchi, A. H., Wohlin, C., and Aurum, A. (2014). "Resources contributing to gaining competitive advantage for open source software projects: an application of resource-based theory." International Journal of Project Management, Vol. 32, No.1, pp. 139-152. DOI: 10.1016/j.ijproman.2013.03.002.

Glass, A. J., Saggi, K. (2010). "Multinational Firms and Technology Transfer.” Social Science Electronic Publishing, Vol. 104, No. 4, pp. 495-513. DOI: 10.1111/1467-9442.00298.

Green, Jr., K. W., Whitten, D., Inman, R. A. (2008). "The impact of logistics performance on organizational performance in a supply chain context." Supply Chain Management: An International Journal, Vol. 13, No. 4, pp. 317-327. DOI: 10.1108/13598 540810882206.

McGrath, G. R. (2013). “Continuous reconfiguration in the transient advantage economy.” Strategy \& Leadership, Vol. 41, No. 5, pp. 17-22. DOI: 10.1108/SL-05-2013-0039.

Harrigan, K. R., and Diguardo, M. C. (2017). "Sustainability of patent-based competitive advantage in the US communications services industry." The Journal of Technology Transfer, Vol. 42, No. 6, pp. 1334-1361. DOI: 10.1007/s10961-016-9515-2.

Helms, M. M. Perspectives on quality and productivity for competitive advantage[J]. Tqm Magazine, 2013, 8(3):5-10. DOI: 10.1108/09544789610118403.

Huang, K. F., Dyerson, R., Wu, L. Y., et al. (2015). "From Temporary Competitive Advantage to Sustainable Competitive Advantage." British Journal of Management, Vol. 26, No. 4, pp. 617-636. DOI: 10.1111/1467-8551.12104.

Huang, W. H., Tserng, H. P., Liao, H. H., et al. (2013). "Contractor financial prequalification using simulation method based on cash flow model." Automation in Construction, Vol. 35, No. 11, pp. 254-262. DOI: 10.1016/j.autcon.2013.05.004.

Hwang, B. G., Zhao, X., Chin, E. W. (2017). "International construction joint ventures between Singapore and developing countries." Engineering Construction \& Architectural Management, Vol. 24, No. 2, pp. 209-228. DOI: 10.1108/ECAM-03-2015-0035.

Kamruzzaman, M., Takeya, H. (2008). "Influence of Technology Responsiveness and Distance to Market on Capacity Building." International Journal of Vegetable Science, Vol. 14, No. 3, pp. 216-231. DOI: 10.1080/19315260802164848.

Kanchanda, K., and Ussahawanitchakit, P. (2011). "Organizational flexibility capability, innovation advantage and firm sustainability: Evidence from electronic manufacturing businesses in Thailand.” International Journal of Business Strategy, Vol.11, No. 3, pp. 122-134.

Lavie, D. (2006). "The competitive advantage of interconnected firms: an extension of the resource-based view." Academy of Management Review, Vol. 31, No. 3, pp. 638-658. DOI: 10.5465/APBPP.2002.7516490

Liang, X., Lu, X., and Wang, L. (2012). "Outward internationalization of private enterprises in China: the effect of competitive advantages and disadvantages compared to home market rivals.” Journal of World Business, Vol. 47, No. 1, pp. 134-144. DOI: 10.1016/j.jwb.2011.02.002.

Linden, T., Cybulski, J. L. (2009). “Application of hermeneutics to studying an experience mining process.” Journal of Information Technology, Vol. 24, No. 3, pp. 231-250. DOI: 10.1057/jit.2009.3.

Liu, C. H., Liao, S. K. (2010). “An empirical study of factors affecting customer loyalty-Taiwan high-speed rail service industry as 
an example." International Journal of Services Operations \& Informatics, Vol. 5, No. 2, pp. 12-18. DOI: 10.1504/IJSOI.2010. 031114.

Lu, W., Shen, L., and Yam, M. (2008). "Critical success factors for competitiveness of contractors: A China study." Journal of Construction Engineering \& Management, Vol. 134, No. 12, pp. 972-982. DOI: 10.1061/(ASCE)0733-9364(2008)134:12(972).

Joliffe, I. T., and Morgan, B. J. (1992). "Principal component analysis and exploratory factor analysis." Statistical Methods in Medical Research, Vol. 1, No. 1, pp. 69-95. DOI: 10.1177/096228029200100105.

Maccallum, R. C., Widaman, K. F., Preacher, K. J., et al. (2001). "Sample Size in Factor Analysis: The Role of Model Error." Multivariate Behavioral Research, Vol. 36, No. 4, pp. 611-637. DOI: 10.1207/S15327906MBR3604_06

Mcgrath, R. G. (2013). “Continuous reconfiguration in the transient advantage economy.” Strategy \& Leadership, Vol. 41, No. 5, pp. 19-24. DOI: 10.1108/SL-05-2013-0039.

Melykh, K., and Melykh, O. (2016). “Implication of Environmental Certification and CSR for Companies' Sustainable Performance in Developing Countries.” Journal of Sustainable Development, Vol. 9, No. 3, pp. 160-169. DOI: 10.5539/jsd. v9n3p160.

$\mathrm{Mu}, \mathrm{S} ., \mathrm{Hu}, \mathrm{C}$. , Chohr, M., et al. (2014). "Assessing risk management capability of contractors in subway projects in mainland China.” International Journal of Project Management, Vol. 32, No. 3, pp. 452-460. DOI: 10.1016/j.ijproman.2013.08.007.

Obloj, T., and Obloj, K. (2006). "Diminishing returns from reputation: do followers have a competitive advantage?" Corporate Reputation Review, Vol. 9, No. 4, pp. 213-224. DOI: 10.1057/palgrave.crr.1550029.

Oddou, G., Szkudlarek, B., Osland, J. S., Deller, J., Blakeney, R., and Furuya, N. (2013). "Repatriates as a Source of Competitive Advantage: How to manage knowledge transfer." Organizational Dynamics, Vol. 42, No. 4, pp. 257-266. DOI: 10.1016/j. orgdyn.2013.07.003.

O'Shannassy, T. (2008). "Sustainable competitive advantage or temporary competitive advantage: Improving understanding of an important strategy construct." Journal of Strategy and Management, Vol. 1, No. 2, pp. 168-180. DOI: $10.1108 / 1755425081092$ 6357.

Porter, M. (1985). Competitive advantage creating and sustaining superior performance. New York: Free Press.

Ram, J., Wu, M. L., and Tagg, R. (2014). "Competitive advantage from ERP projects: Examining the role of key implementation drivers." International Journal of Project Management, Vol. 32, No. 4, pp. 663-675. DOI: 10.1016/j.ijproman.2013.08.004.

Rendon, R., Apte, U., Dixon, M. (2015). “Contractor Past Performance Information: An Analysis of Assessment Narratives and Objective Ratings.” Developmental Neuroscience, Vol. 22, No. 22, pp. 384-92. DOI: 10.1159/000017464.

San Kim, D., Baek, D. H., and Yoon, W. C. (2010). "Development and evaluation of a computer-aided system for analyzing human error in railway operations." Reliability Engineering \& System Safety, Vol. 95, No. 2, pp. 87-98. DOI: 10.1016/j.ress. 2009.08.005.

San Kim, D., and Yoon, W. C. (2013). "An accident causation model for the railway industry: Application of the model to 80 rail accident investigation reports from the UK.” Safety Science, Vol. 60, pp.57-68. DOI: 10.1016/j.ssci.2013.06.010.

Santos-Vijande, M. L., López-Sánchez, J. Á., and Trespalacios, J. A. (2012). “How organizational learning affects a firm's flexibility, competitive strategy, and performance.” Journal of Business Research, Vol. 65, No. 8, pp. 1079-1089. DOI: 10.1016/j.jb usres.2011.09.002.

Scheepbouwer, E., Gransberg, D. D., Puerto, C. L. D. (2017). "Construction engineering management culture shift: Is the lowest tender offer dead?" Frontiers of Engineering Management, Vol. 4, No. 1, pp. 49-57. DOI: 10.15302/J-FEM-2017014.

Shen, L. Y., Lu, W. S., and Yam, M. C. (2006). “Contractor key competitiveness indicators: A China study.” Journal of Construction Engineering \& Management, Vol. 132, No. 4, pp. 416-424. DOI: 10.1061/(ASCE)0733-9364(2006)132:4(416).

Sun, Q., Feng, X., and Kai, B. (2011). "Operation and Organization Management of High-speed Railway in Japan.” Journal of Transportation Systems Engineering \& Information Technology, Vol. 11, No.5, pp. 11-16. DOI:10.1016/s1570-6672(10)60138-9

Tabachnick, B. G., and Fidell, L. S. (2001). Computer-assisted research design and analysis. Allyn and Bacon, Boston.

Tan, Y., Shen, L., and Yao, H. (2011). "Sustainable construction practice and contractors' competitiveness: A preliminary study." 
Habitat International, Vol. 35, No. 2, pp. 225-230. DOI: 10.1016/j.habitatint.2010.09.008.

Thomas, L. G., and D'Aveni R. (2009). “The changing nature of competition in the us manufacturing sector, 1950--2002.” Strategic Organization, Vol: 7, No. 4, pp. 387-431. DOI: 10.1177/1476127009348561.

Thompson, B., Grimm, L.G. and Yarnold, P. R. (2000). Ten Commandments of Structural Equation Modeling. American Psychological Association, Washington.

Utsunomiya, M., and Hodota, K. (2011). "Financial lessons from Asian experience in constructing and operating high speed train networks." Transportation, Vol. 38, No. 5, pp. 753-764. DOI: 10.1007/s11116-011-9348-7.

Vickerman, R. (2018). “Can high-speed rail have a transformative effect on the economy?” Transport Policy, Vol. 62, pp. 31-37. DOI: 10.1016/j.tranpol.2017.03.008.

Vogel, R., and Güttel, W. H. (2013). "The dynamic capability views in strategic management: a bibliometric review." International Journal of Management Reviews, Vol. 15, No. 4, pp. 426-446. DOI: 10.1111/ijmr.12000.

Wen, Q., and Qiang, M. (2016). “Enablers for organizational project management in the Chinese context.” Project Management Journal, Vol. 47, No. 1, pp. 113-126. DOI: 10.1002/pmj.21565.

Wright, P. M., Mcmahan, G. C., Mcwilliams, A. (2016). "Human resources and sustained competitive advantage: a resource-based perspective." International Journal of Human Resource Management, Vol. 5, No. 2, pp. 301-326. DOI: 10.1080/095851994000 00020.

Wright, S., Eid, E. R., and Fleisher, C. S. (2009). "Competitive intelligence in practice: empirical evidence from the UK retail banking sector.” Journal of Marketing Management, Vol. 25, No. 9-10, pp. 941-964. DOI: 10.1362/026725709X479318.

Wu, H. Y., Lin, Y. J., Chien, F. L., and Hung, Y. M. (2011). “A study on the relationship among supplier capability, partnership and competitive advantage in Taiwan's semiconductor industry.” International Journal of Electronic Business Management, Vol. 9 , No. 2, pp. 122-138.

Zhang, N., Deng, X., Zhao, X., and Chang, T. (2019). "Exploring the Sources of Contractors' Competitive Advantage on International HSR Construction Projects.” International Journal of Civil Engineering, Vol. 17, No. 7, pp. 1115-1129. DOI: 10.1007/s40999-018-03 73-1.

Zhang, S. (2012). "International competitiveness of China's wind turbine manufacturing industry and implications for future development." Renewable and Sustainable Energy Reviews, Vol. 16, No. 6, pp. 3903-3909. DOI: 10.1016/j.rser.2012.03.006.

Zhou, P. F., Han, B. M., Zhang, Q. (2014). Survey on high-speed railway train plan design issues, Applied Mechanics and Materials. Trans Tech Publications, pp. 489-492. 